\title{
IMPLEMENTASI PERATURAN DAERAH NOMOR 8 TAHUN 2013 TENTANG GARIS SEMPADAN JALAN DI KABUPATEN KUNINGAN
}

\author{
Hani Hadiyanti, Haris Budiman dan Bias Lintang Dialog \\ Fakultas Hukum Universitas Kuningan, Kuningan, Indonesia \\ E-mail : hanyhadiyanti12@gmail.com
}

Sitasi : Hadiyanti, Hani., Haris Budiman \& Bias Lintang Dialog. Implementasi Peraturan Daerah Nomor 8 Tahun 2013 Tentang Garis Sepadan Jalan di Kabupaten Kuningan. UNIFIKASI : Jurnal I/mu Hukum, 5.1 (2018), 1-10. DOI https://doi.org/10.25134/unifikasi.v5i1.730

Naskah diterima : 9-12-2017 Naskah direvisi : 23-1-2018

Naskah disetujui : 5-2-2018

\begin{abstract}
Abstrak : Desentralisasi yang berkembang di Indonesia memiliki suatu tujuan dalam perkembangan ekonomi di Indonesia, yaitu meningkatkan perekonomian dari sector terkecil yang terdapat di daerah. Berdasarkan hal tersebut pemerintah daerah mendapatkan delegasi kewenangan dari pemerintahan pusat untuk membentuk suatu kebijakan yang mendukung peningkatan perekonomian daerah. Tujuan penelitian ini adalah untuk mengetahui dan menganalisis bagaimana pengaturan tentang Bangunan yang melanggar ketentuan Garis Sempadan Jalan di Pasar Darma Kabupaten Kuningan sesuai Peraturan Daerah Nomor 8 Tahun 2013 tentang Garis Sepadan Jalan dan Bagaimana Implementasi dari Pasal 6 Peraturan Daerah Nomor 8 tahun 2013 tentang Garis Sempadan Jalan di Pasar Darma Kecamatan Darma Kabupaten Kuningan?. Penelitian ini dilakukan dengan metode pendekatan yuridis emipis dengan spesifikasi penelirian deskriptif analitis yang melibatkan penelitian kepustakaan dan penelitian lapangan dengan menggunakan data primer dan data sekunder serta metode penarikan kesimpulan analisis yuridis kualitatif, data yang terkumpul kemudian dianalisis secara kualitatif. Hasil penelitian ini menemukan bahwa ketidaksesuaian fungsi ruang garis sempa dan jalan yang itu terdapat bangunan di area garis sempadan jalan tersebut. Peraturan Daerah Nomor 8 Tahun 2013 tentang Garis Sepadan Jalan terdapat ketentuan pidana bagi pelanggar area garis sempadan jalan. Selain itu implementasi dari Pasal 6 Peraturan Daerah Kabupaten Kuningan Nomor 8 Tahun 2013 tidak sesuai dengan yang diharapkan aturan tersebut, yaitu jarak garis sempadan jalan yang seharusnya 14.5 meter dari garis tengah jalan ditemukan hanya kurang dari 10 meter dari garis tengah jalan. Kesimpulannya perlunya dilakukan penataan dan sosialisasi kepada masyarakat terkait dengan garis sepadan jalan.
\end{abstract}

Kata Kunci : izin, jalan, pelanggaran

\section{THE IMPLEMENTATION OF REGIONAL REGULATION NUMBER 8 YEAR 2013 ABOUT BOUNDARY LINE IN KUNINGAN REGENCY}

\begin{abstract}
The decentralization that developed in Indonesia has a goal in economic development in Indonesia is to improve the economy of the smallest sector in the region. Based on this the local government gets delegation of authority from the central government to form a policy that supports the improvement of the regional economy. The purpose of this study is to find out and analyze how the arrangement of the building that violates the provisions of the boundary line in Pasar Darma Kuningan district according to Local Regulation No. 8 of 2013 on the boundary line and how to implementation of Article 6 of Regional Regulation No. 8 of 2013 on boundary line in Darma Market, Darma District, Kuningan Regency. This research using the method of juridical emipis approach with descriptive analytical specification involving library research and field research using primary, secondary data and method of conclusion of qualitative juridical analysis, analyzed qualitatively. The results of this study found that the mismatch of boundary line and building space functions in the area of the boundary line. In the regional regulations there is a criminal provision for offenders of the boundary line area. The implementation of Article 6 of Regional Regulation of Kuningan Regency Number 8 of 2013 is not in accordance with the regulation, ie the distance of the boundary line that should be 14.5 meters from the center line of the road is found to be less than 10 meters from the center line of the road. The conclusion, the need for structuring and socialization to the community related to boundary line
\end{abstract}

Keywords : licensing, road boarder, violation.

\section{PENDAHULUAN}

Indonesia merupakan negara hukum yang sistem pemerintahannya sebagian menganut sistem desentralisasi. ${ }^{1}$

${ }^{1}$ Kansil, C.S.T., 2005, Sistem Pemerintahan Indonesia, Jakarta : PT. Bumi Aksara, hlm. 56.
Desentralisasi menurut Pasal 1 Undangundang Nomor 23 Tahun 2014 tentang Pemerintah Daerah adalah: "penyerahan wewenang pemerintah ke pemerintah daerah otonom guna mengatur dan mengurus segala 
UNIFIKASI : Jurnal IImu Hukum, Volume 05 Nomor 01, Januari 2018

urusan pemerintahan dalam sistem pemerintahan Indonesia."

Tujuan dari sistem desentralisasi lainnya adalah mensejahterakan masyarakat yang direalisasikan melalui pelayanan kepada masyarakat (public service). ${ }^{2}$ Salah satu contoh yang memerlukan pelayanan publik dengan baik adalah pelayanan dalam izin mendirikan bangunan yang selanjutnya disingkat IMB. IMB sendiri terdapat berbagai aspek yang erta kaitannya dengan pengaturan perihal agrarian. Pemerintah melalui kewenangannya memiliki hak dasar suatu tanah dan bangunan yang berupa hak menguasai Negara dalam pengelolaan agraria yang berada di wilayah Indonesia sesuai dengan ketentuan yang tercantum dalam Undang-undang Pokok Agraria. ${ }^{3}$ Garis Sepadan Jalan atau GSJ yang merupakan batas terdepan pagar halaman yang boleh didirikan menjadi salah satu syarat yang harus dipenuhi agar IMB bisa didapatkan. ${ }^{4}$

Fungsi utama GSJ, yaitu agar setiap bangunan dibangun dengan kepedulian terhadap lingkungan. GSJ yang pada praktiknyha sering disalahgunakan fungsinya, terutama dijadikan lahan parkir dan pedagang bebas seperti yang terjadi di Jalan Pasar Darma yang terletak di Kecamatan Darma Kabupaten Kuningan Jawa Barat, yang merupakan jalan Lokal Primer yaitu jalan yang menghubungkan secara berdaya guna pusat kegiatan nasional dengan pusat kegiatan lingkungan, pusat kegiata wilayah denga pusat kegiatan lingkungan, antar pusat kegiatan lokal, atau pusat kegiatan lokal dengan pusat kegiatan lingkungan, serta antar pusat kegiatan lingkungan. ${ }^{3}$

2 Nugroho, 2004, Kebijakan Publik, Formulasi Implemetasi dan Evaluasi. Gramedia. Jakarta. HIm. 86.

3 A. Ridwan Halim, 2007. Pengantar Hukum Indonesia Dalam Tanya Jawab, Bogor: Ghalia Indonesia, HIm. 93.

${ }^{4}$ Ibid.
p-ISSN 2354-5976, e-ISSN 2580-7382

https://journal.uniku.ac.id/index.php/unifikasi

Kabupaten Kuningan sendiri telah memiliki aturan khusus mengenai GSJ, yaitu Peraturan Daerah Kabupaten Kuningan Nomor 8 tahun 2013. Sayangnya pelaksanaan aturan tersebut belum dioptimalisasi, seperti yang terjadi di Jalan Pasar Darma yang menyalahi ketentuan Pasal 6 Peraturan Daerah Kabupaten Kuningan Nomor 8 tahun 2013 yang mengatur perihal jarak GSJ seharusnya diterapkan dio Jalan PAsar Darma. Kebijakan pengelolaan jalan harus melalui berbagai upaya yaitu preventif dan represif. ${ }^{5}$ Kebijakan penataanruang khususnya sepadan jalan harus memperhatikan Hak Asasi Manusia baik sebagai pengguna jalan maupun sebagai masyarakat yang berdampingan dengan jalan. ${ }^{6}$

\section{RUMUSAN MASALAH}

Adapun yang menjadi pokok permasalahan yang akan menjadi fokus perhatian utama yang akan dibahas dalam penulisan ini yaitu Bagaimana pengaturan tentang Bangunan yang melanggar ketentuan Garis Sempadan Jalan di Pasar Darma Kabupaten Kuningan sesuai Peraturan Daerah Nomor 8 Tahun 2013? Bagaimana Implementasi dari Pasal 6 Peraturan Daerah Nomor 8 tahun 2013 mengenai Garis Sempadan Jalan di Pasar Darma Kecamatan Darma Kabupaten Kuningan?

\section{METODE PENELITIAN}

Penelitian merupakan usaha untuk memperoleh fakta, dengan cara

\footnotetext{
${ }^{5}$ Ety Isworo, Tinjauan Yuridis Pelaksanaan Penertiban Hunian Liar Di Kota Solo, Jurisprudence, VOL . 1, NO . 1 . Juli $2012: 89-102$

${ }^{6}$ Haris Budiman, Pelanggaran Hak Asasi Manusia Dalam Kebijakan Daerah Di Bidang Tata Ruang Di Kabupaten Kuningan, Jurnal Unifikasi, ISSN 2354-5976 Vol. 04 Nomor 01 Januari 2017, hlm. 25-34. https://doi.org/10.25134/unifikasi.v4i1.475.
} 
UNIFIKASI : Jurnal IImu Hukum, Volume 05 Nomor 01, Januari 2018

mengumpulkan dan menganalisis data yang dilakukan dengan teliti, jelas, dan dapat dipertanggung jawabkan. Adapun metode penelitian yang dipergunakan dalam penulisan ini dengan cara sebagai berikut:

1. Spesifikasi Penelitian, Berisifat Deskriptif Analisis yaitu penelitian yang dimaksudkan untuk memberikan data yang seteliti mungkin tentang realisasi sosial dari fatka-fakta yang dikemukaka dari garis sempadan jalan, yang untuk selanjutnya penelitian ini dilakukan upaya analisis dengan berdasarkan sistematika hukum, yaitu penelitian yang tujuan pokoknya adalah untuk mengadakan identifikasi terhadap disiplin ilmu hukum, khususnya hukum perizinan yang berkenaan dengan garis sempadan jalan.Sumber data yang digunakan dalam penelitian ini adalah Sumber Data Primer yaitu sumber data yang diperoleh secara langsung dari objek penelitian. ${ }^{7}$

2. Metode Pendekatan, Berdasarkan rumusan masalah dan tujuan penelitian, maka pendeketan yang digunakan lebih di titik beratkan pada Yuridis Empiris. Yuridis Empiris yaitu penelitian hukum yang menggunakan data primer atau data lapangan yang dilakukan untuk menganalisa tentang bagaimana suatu peraturan/perundang-undangan atau hukum yang sedang berlaku secara efektif sesuai dengan peraturan hukum positif yang berlaku saat ini. Dalam hal ini pendekatan yuridis digunakan untuk meneliti efektifitas suatu peraturan dan penelitian yang ingin mencari hubungan (korelasi) antara berbagai gejala atau variabel sebagai alat pengumpul datanya terdiri dari studi dokumen, pengamatan (observasi), dan wawancara (interview).

\footnotetext{
7 Soejono Soekamto, 2001, Metodologi Penelitian dan
} Penulisan Hukum, Jakarta : Rajagrafindo. hlm, 15.
p-ISSN 2354-5976, e-ISSN 2580-7382 https://journal.uniku.ac.id/index.php/unifikasi

3. Tahap Penelitian, Penulis melakukan penelitian yang dimulai dengan meneliti lapangan / keadaan lokasi penelitian dan dilanjutkan dengan menganalisis permasalahan sesuai data yang di dapat dari penelitian lapangan dengan teori hukum yang dijadikan acuan oleh penulis.

4. Teknik Pengumpulan Data, Kumpulan informasi / data yang disusun dan disajikan oleh penulis yang menggunakan teknik non random sampling adalah data yang memungkinkan adanya penarikan kesimpulan dan pengambilan tindakan yang mengerucut pada suatu objek penelitian secara khusus. Penyajian dari kumpulan informasi / data yang sering digunakan adalah dalam bentuk naratif, bentuk matriks, grafik dan bagan.

5. Alat Pengumpul Data Kumpulan informasi /data disusun oleh penulis berdasarkan observasi lapangan yang dilakukan penulis terhadap objek penelitian dan disusaikan dengan wawancara yang dilakukan dnegan narasumber yang berkompeten.

6. Analisis Data, Penelitian dilakukan di Jalan Pasar Darma Kecamatan Darma Kabupaten Kuningan Jawa Barat. Penelitian dilakukan kepada pemilik bangunan pasar yang melanggar ketentuan garis sempadan jalan, karena Jalan Pasar Darma merupakan jalan raya kolektor primer yang menghubungkan antar pusat kegiatan nasional yaitu sebagai jalan transportasi dan pusat kegiatan lokal yaitu sebagai kegiatan pasar dalam Pasal 6 Peraturan Daerah Nomor 8 Tahun 2013 menyebutkan bahwa bangunan harus berada diluar garis sempadan jalan dengan jarak tidak kurang dari 22,5 meter dari AS jalan. Sementara dalam pelaksanaannya bangunan yang berada di 
UNIFIKASI : Jurnal IImu Hukum, Volume 05 Nomor 01, Januari 2018

Jalan Pasar Darma ternyata hanya kurang dari 10 meter.

\section{PEMBAHASAN}

\section{Pengaturan Garis Sempadan Jalan di Kabupaten Kuningan.}

Kuningan sebagai kabupaten yang terletak diujung provinsi Jawa Barat memiliki kepentingan yang cukup signifikan perihal pengaturan jalan, oleh karenanya terbit suatu pengaturan khusus yang mengatur mengenai jalan yang dititik beratkan pada Garis Sempadan Jalan yaitu Peraturan Daerah Kabupaten Kuningan Nomor 8 Tahun 2013. Adapun isi dari peraturan tersebut diantaranya adalah mengatur tentang kriteria atau ketentuan Garis Sempadan Jalan, apa yang diperbolehkan dan dilarang dilakukan terhadap suatu batas jalan tertentu serta sanksi bagi yang melanggar. ${ }^{8}$

Pengaruh perkembangan zaman, seperti globalisasi mempengaruhi kebutuhan hidup manusia dalam bermasyarakat menjadi sangat beragam, terutama dalam bidang ekonomi. Masyarakat berbagai kalangan berlomba-lomba meningkatkan taraf atau kualitas hidup secara ekonomi untuk melebihi pesaing-pesaingnya di bidang ekonomi. Berdasarkan hal tersebut, masyarakat yang berperan sebagai pelaku usaha dituntut kreatif dalam mengembangkan atau memperluas usahanya yang sedang berjalan untuk membangun suatu iklim perekonomian yang kondusif.

Rencana pembangunan perekonomian yang terarah yang disusun oleh Pemerintah sebagai salah satu usaha dalam mengembangkan perekonomian nasional mempertimbangkan segala aspek yang diantaranya aspek paling utama yang menjadi

${ }^{8}$ Hardiyatmo, Hary christadi. 2015. Pemeliharaan Jalan Raya. Gadjah Mada University Press. Yogyakarta. HIm. 66.
p-ISSN 2354-5976, e-ISSN 2580-7382

https://journal.uniku.ac.id/index.php/unifikasi

dasar pelaksanaan rencana tersebut adalah aspek hukum. Aspek hukum disini berupa suatu keputusan atau kebijakan yang dibuat oleh Pemerintah sebagai kunci dari pelaksanaan rencana, hal tersebut dikenal dengan istilah izin. Izin menurut Utrecht adalah bilamana pembuatan peraturan tidak umumnya melarang suatu perbutaan tetapi masih juga memperkenankannya asala saja diadakan secara yang ditentuakan untuk masing-masing hal konkrit maka perbuatan administrasi Negara memperkenankan perbuatan tersebut bersifat izin (vegunning).

Izin merupakan bagian dari hukum administrasi yang berbentuk keputusan yang memiliki pengertian menurut Sjachran Basah yaitu perbuatan hukum administrasi Negara bersegi satu yang menghasilkan peraturan dalam hal kontreo berdasarkan persyaratan dan prosedur sebagaimana yang ditetapkan oleh ketentuan perundang-undangan yang berlaku. Begitu pula dengan ketentuan Garis Sempadan Jalan di Kabupaten Kuningan yang erat kaitannya dengan izin yang diperoleh atas hak yang berada di area Garis Sempadan Jalan tersebut. Izin yang dimaksud oleh hal tersebut di atas adalah izin yang berbentuk tertulis yang merupakan suatu keputusan administrasi Negara atau dikenal dengan istilah beschiking yang dapat dijadikan alat bukti di pengadilan dan diterbitkan untuk tujuan pengendalian.

Adapun detail dari ketentuan Garis Sempadan Jalan yang diberlakukan di seluruh jalan di Kabupaten Kuningan sesuai dengan Pasal 6 Peraturan Daerah Kabupaten Kuningan Nomor 8 Tahun 2013 diantaranya :

1. Garis Sempadan Jalan pada Jalan Primer Kolektor

2. Garis Sempadan Jalan padaJalan Primer Lokal

3. Garis Sempadan Jalan padaJalan Primer Lingkungan 
UNIFIKASI : Jurnal IImu Hukum, Volume 05 Nomor 01, Januari 2018

4. Garis Sempadan Jalan padaJalan Sekunder Kolektor

5. Garis Sempadan Jalan padaJalan Sekunder Lokal

6. Garis Sempadan Jalan pada Jalan Sekunder Lingkungan

Pemerintah memperhatikan secara khusus perihal pengaturan Garis Sempadan Jalan terebut dengan mengkoordinasikan fungsi jalan tersebut dengan berbagai aspek dan instansi lainnya yang berkentingan pula atas lahan yang ada di jalan tersebut, diantaranya adalah Badan Pertanahan Nasional atas fungsi tanah serta pengaturan perihal mendirikan bangunan melalui Izin Mendirikan Bangunan. 9 Izin tersebut diberikan dengan memperhatikan pinsip good governance diantaranya adalah Asas Transparansi, Asas Akuntabilitas, Asas Kondisional, Asas Partisipatif, Asas Kesamaan Hak serta Asas Keseimbangan Hak dan Kewajiban.

Mendirikan bangunan yang masih dalam ruang Garis Sempadan Jalan dimanapun, khususnya untuk daerah Kabupaten Kuningan merupakan pelanggaran terhadap Peraturan Daerah Kabupaten Kuningan Nomor 8 Tahun 2016. Berdasarkan regulasi tersebut, para prinsipnya setiap bangunan gedung harus memenuhi persyaratan administratif dan persyaratan teknis sesuai dengan fungsinya. Bangunan yang dimaksud tersebut dapat berupa bangunan yang merupakan tempat tinggal / kediaman masyarakat maupun tempat kegiatan ekonomi yang tidak memiliki izin. Pada perlintasan antar kabupaten dan provinsi yang mana Kabupaten Kuningan juga memiliki perlintasan tersebut banyak ditemukan bangunan untuk kegiatan ekonomi tanpa izin yang tidak jarang dijadikan sebagai tempat istirahat (rest area) bagi pengemudi

${ }^{9}$ Zulkifli Arif. 2014. Pengelolaan Kota Berkelanutan. Yogyakarta: Graha IImu.. HIm. 45.
p-ISSN 2354-5976, e-ISSN 2580-7382

https://journal.uniku.ac.id/index.php/unifikasi

kendaraan yang melintas diperlintasan tersebut. Hal tersebut dianggap lumrah dilakukan, namun sayangnya butuh penegakan hukum yang akan mewujudkan suatu kepastian hukum agar masyarakat mengetahui apa yang sebenarnya dibolehkan dan dilarang oleh peraturan. ${ }^{10}$

Pengaruh perkembangan zaman, seperti globalisasi mempengaruhi kebutuhan hidup manusia dalam bermasyarakat menjadi sangat beragam, terutama dalam bidang ekonomi. Masyarakat berbagai kalangan berlombalomba meningkatkan taraf atau kualitas hidup secara ekonomi untuk melebihi pesaingpesaingnya di bidang ekonomi. Berdasarkan hal tersebut, masyarakat yang berperan sebagai pelaku usaha dituntut kreatif dalam mengembangkan atau memperluas usahanya yang sedang berjalan untuk membangun suatu iklim perekonomian yang kondusif. Berdasarkan hal tersebut dapat disimpulkan latar belakang mengapa kondisi Pasar Darma yang bersinggungan langsung denga batas Garis Sempadan Jalannya terdapat pelanggaran yang sulit untuk ditertibkan.

Pasal 14 Peraturan Daerah Kabupaten Kuningan No 8 Tahun 2013 berisikan larangan mendirikan bangunan disekitar ruang Garis Sempadan Jalan, yaitu :

"Setiap Orang dilarang mendirikan bangunan pada ruang Garis Sempadan Jalan yang mengakibatkan terganggunya fungsi jalan sebagaimana dimaksud dalam Pasal 5".

Terganggunya fungsi jalan yang dimaksud di atas adalah terganggunya arus lalu lintas di jalan tersebut, hal itu dikarenakan akibat adanya bangunan ruang Garis Sempadan Jalan yang menjadi titik berhenti sementara para pengemudi yang akhinya memarkir

\footnotetext{
${ }^{10}$ Trbus Wahyudi, Artikel lepas dengan judul Urgensi Sistem Hukum di Indoensia dalam Persfektif Pembentukan Hukum Nasional yang erfalsafah Pancasila.
} 
UNIFIKASI : Jurnal IImu Hukum, Volume 05 Nomor 01, Januari 2018

kendaraannya di bahu jalan, dengan kata lain mempersempit lajur lalu lintas. ${ }^{11}$

Sanksi yang dikenakan bagi pendiri bangunan di ruang Garis Sempadan Jalan sesuai dengan ketentuan Peraturan Daerah Kabupaten Kuningan Nomor 8 Tahun 2013 dapat berupa penertiban dan/atau pembongkaran bangunan setelah sebelumnya diperingatkan oleh Penyidik Pegawai Negeri Sipil (PPNS) yang menangani penyidikan dugaan pelanggaran ruang Garis Sempadan Jalan. Apabila pendiri bangunan tersebut tidak bersedia untuk dilakuakn penertiban dan/atau pembongkaran maka pendiri tersebut akan dikenakan pembebanan biaya paksa yang akan disetorkan ke kas daerah. ${ }^{12}$ Namun, terdapat ketentuan pidana jika pelanggaran pada pasal 14 Peraturan Daerah Kabupaten Kuningan Nomor 8 Tahun 2013 dilakukan, yaitu diancam dengan pidana kurungan paling lama 3 (tiga) tahun kurungan atau dikenakan sanksi denda sebesar Rp. 50.000.000,- (lima puluh juta rupiah).

\section{Implementasi Peraturan Daerah Kabupaten} Kuningan Nomor 8 Tahun 2013 tentang Garis Sempadan Jalan di Kabupaten Kuningan.

Telah dijelaskan sebelumnya mengenai keberadaan Kabupaten Kuningan yang berada diperbatasan antar provinsi, yaitu provinsi Jawa Barat dengan provinsi Jawa Tengah Lebih khusus ruas jalan yang menghubungkan antar kabupaten dan antar provinsi tersebut disebut dengan istilah jalan strategisprovinsi yang difungsikan sebagai perlintasan alternative selain perlintasan utama yang notabenenya adalah jalur Pantura.

Fungsi sebagai jalan strategis provinsi tersebutlah yang menjadikan Jalan Raya

\footnotetext{
${ }^{11}$ Hardiyatmo, Hary Christady. Op. Cit.

${ }^{12}$ Adrian Sutendi, 2011. Hukum Perizinan dalam Sektor Pelayanan Publi. Jakarat: Sinar Grafika. HIm. 17.
}

p-ISSN 2354-5976, e-ISSN 2580-7382

https://journal.uniku.ac.id/index.php/unifikasi

depan Pasar Darma tersebut menjadi pusat keramaian, baik itu lalu lintas yang ramai, menjadi pusat pertemuan, bahkan kegiatan di Pasar Darma yang mendominasi sebagian dari fungsi jalan tersebut. Pemerintah setempat, melalui pemerintah desa Darma berusaha untuk memberikan edukasi perihal penggunaan sebagaian fungsi jalan yang tidak tepat guna tersebut, akan tetapi hal tersebut belum dapat dimaksimalkan. Kendala yang dihadapi oleh aparat pemerintah dalam dipengaruhi berebagai factor.

Jalan Raya depan Pasar Darma merupakan jalan provinsi yang termasuk kedalam kategori Jalan Sedang dengan fungsi sebagai Jalan Lokal Primer, yaitu jalan yang menghubungkan antara pusat kegiatan lingkungan, pusat kegiatan wilayah dengan pusat kegiatan lingkungan anatar pusat kegiatan lokal atau pusat kegiatan local dengan pusat kegiatan lingkungan, serta antar pusat kegiatan lingkungan. Jalan Raya depan Pasar Darma tersebut merupakan jalan terusan dari Jalan Besar Lokal Primer antar kota maupun antar provinsi yang sehariharinya dilalui oleh kendaraan yang memiliki roda lebih dari 6 (enam) dengan kecepatan minimum 20 (dua puluh) $\mathrm{km} / \mathrm{jam}$. Pasal 6 Peraturan Daerah Kabupaten Kuningan No 8 Tahun 2013 pengaturan ruang Garis Sempadan Jalan atas Jalan Raya depan Pasar Darma memenuhi kriteria ayat (2) huruf b, yang mana ketentuannya berisikan sebagai berikut:

"Jarak Garis Sempadan Jalan pada seluruh ruas jalan di wi layah Kabupaten Kuningan, untuk jalan yang masuk kategori jalan sedang ditentukan dengan ukuran sebagai berikut:

b. Jalan Lokal Primer, tidak kurang dari 14,5 (empat belas koma lima) meter diukur dari As Jalan." 
UNIFIKASI : Jurnal IImu Hukum, Volume 05 Nomor 01, Januari 2018

Berdasarkan pada ketentuan tersebut, sudah seharusnya Jalan Raya depan Pasar Darma memenuhi kriteria ruang Garis Sempadan Jalan di atas. Namun sayangnya, hasil penelitian di lapangan menemukan kondisi dimaan bah jalan di Pasar Darma dijadikan sebagai sarana berdagang bagi Pedagang Kaki Lima dan menjadi lahan parkir liar yang diperuntukan bagi pengunjung Pasar Darma itu sendiri. Tidak sampai 14,5 (empat belas koma lima) meter ruang untuk Garis Sempadan Jalan, pada kenyataannya kurang dari 10 (sepuluh) meter ruang Garis Sempadan Jalan berfungsi sebagaimana mestinya.

Penertiban yang dilakukan oleh Pemerintah setempat (pemerintah desa darma) adalah teguran terhadap pedagang yang melewati batas Pasar Darma, yaitu pedagang yang berjualan di area bahu jalan yang notabenenya melanggar ruang Garis Sempadan Jalan. Pemeriksa Izin Mendirikan Bangunan (IMB) dilakukan pula sebagai rangkaian dari penertiban, jika tidak disertai oleh IMB maka bangunan tersebut akan mengalami pembongkaran oleh petugas yang berwenang, sedangkan jika terdapat IMB maka tugas peyidiklah yang akan meninjau lebih lanjut suatu pelanggaran dapat diproses secara hukum. Selain upaya penertiban tersebut di atas, sebagai tanda pemeliharaan jalan pemerintah yang merupakan perpanjangan tangan dari Dinas Perhubungan Provinsi Jawa Barat menerapkan sistem retribusi bagi seluruh pedagang di Pasar Darma. Besar retribusi tersebut sangat kecil dibandingkan dengan penghasil pedangan di Pasar Darma. Dana retribusi tersebut akan diteruskan oleh Petugas Desa Darma ke kas Dinas Perhubungan Provinsi Jawa Barat yang akan dialokasikan lebih lanjut untuk pemeliharaan jalan, salah satunya Jalan raya depan Pasar Darma.
p-ISSN 2354-5976, e-ISSN 2580-7382

https://journal.uniku.ac.id/index.php/unifikasi

Sebuah peraturan khususnya Peraturan Daerah Nomor 8 Tahun 2013 dalam suatu pembanguanan yang berkelanjutan jhususnya dalam bidang ekonomi akan berakibat pada pembentukan lingkungan di Kecamatan Darma itu sendiri dan prilaku masyarakatnya juga. Lawrence $M$. Friedman berpendapat bahwa padu padan antara komponen hukum dengan prilaku masyarakat hukum sangatlah penting dalam membangun suatu sistem huukum di masyarakat. ${ }^{13}$ Menurutnya sistem hukum terdiri darilegal suubstance (subtansi hukum), Legal structure (struktur hukum) dan Legal culture (budaya hukum) yang ketiganya sangat dipengaruhi oleh kondisi yang sedang terjadi, baik itu moderenitas yang bertahap pada suatu golongan masyarakat atau pengaruh globalisasi yang mempengaruhi segala faktor kehidupan bermasyrakat. Faktor-faktir yang mempengaruhi hal tersebut diantaranya adalah factor ekonomi, social dan budaya dari masyarakat itu sendiri. Untuk mendekati pencapaian situasi yang ideal dimana apa yang diharapkan sesuai dengan apa yang terjadi (das sollen dan sein) perlu sutau kontrol sosial atau kendali sosial yang memenimalisir masalah dalam perubahan keadaan sosial. ${ }^{14}$ Interaksi sosial pun sangat berperan dalam efektiitas suatu aturan dimana saling mempengaruhi antar individu maupun masyarakat membatu mempersingkat proses sosialisasi untuk menjadi bahan evaluasi dari penerapan aturan baru.Pentingnya sosialisasi dan pemahaman hukum tidk luput menjadi bahan evaluasi bersama untuk mencapai tujuan dari suatu aturan itu dibentuk.

\footnotetext{
${ }^{13}$ R. Subekti. 1979. Beberapa Pemeikiran Mengenai Sistem Hukum Nasional yang akan Datang. Lertas Kerja Seminar Hukum Nasional IV. Jakarta

${ }^{14} \mathrm{Kansitl}$ C.S.T, 2005. Sistem Pemerintahan Indonesia. Jakarta : Bumi Kasara. HIm. 106.
} 
UNIFIKASI : Jurnal IImu Hukum,

Volume 05 Nomor 01, Januari 2018

\section{SIMPULAN}

Hasil penelitian dan penjambaran di atas, peneliti memiliki kesimpulan sebagai berikut

1. Peraturan Daerah Kabupaten Kuningan Nomor 8 Tahun 2013 mengatur secara rinci pengaturan Garis Sempadan Jalan di seluruh ruas jalan yang ada di wilayah Kabupaten Kuningan. Dalam prakteknya, terdapapt beberapa ketidaksesuaian fungsi ruang Igaris Sempadan Jalan, diantaranya bangunan yang berada di ruang tersebut. Hal itu merupakan pelanggaran dari Pasal 14 Peraturan Daerah Kabupaten Kuningan Nomor 8 Tahun 2013 yang dapat dikenakan sanksi berupa penertiban dan/atau pembongkaran bangunan yang disertai dengan biaya paksa penegakan hukum apabila pendiri/pemiliki bangunan menolak untuk ditertibkan. Terdapat ketentuan pidana yang dapat dikenakan bagi pelanggar dengan proses penyidikan melalui Penyidik Pegawai Negeri Seipil (PPNS) di lingkungan Pemerintah Daerah KAbupate Kuningan.

2. Implementasi Pasal 6 Peraturan Daerah Kabupaten Kuningan Nomor 8 Tahun 2013 mengenai Garis Sempadan Jalan di Pasar Darma Kecamatan Darma Kabupaten Kuningan pada praktiknya ditemukan ketidaksesuaian, diantaranya ruang Garis Sempadan Jalan yang seharusnya diukur 14,5 (empat belas koma lima) meter dari garis tengah jalan tidak sesuai dengan kondisi saat ini, yaitu kurang dari 10 (sepuluh) meter ruang Garis Sempadan Jalan yang berfungsi sebagaimana mestiya. Hal ini ditindak oleh Pemerintah setempat dan disesuaikan dnegan kebijakan yang dikeluarkan oleh Dinas Perhubungan Provinsi Jawa Barat yang menerapkan sistem retribusi bagi seluruh pedagang di Pasar Darma guna
p-ISSN 2354-5976, e-ISSN 2580-7382

https://journal.uniku.ac.id/index.php/unifikasi

pemeliharaan Jalan Provinsi yang notabenenya adalah Jalan Raya depan Pasar Darma.

Idealnya tujuan dari pembentukan suatu aturan yang baru dapat optimal berlaku di masyarakat, menjadikan situasi dan kondisi menjadi lebih baik dari sebelum berlakunya aturan yang belaku. Namun hal tersebut merupakan kondisi ideal yang membutuhkan waktu yang cukup lama mengingat berbagai faktor mempengaruhi efektivitas berlakunya suatu aturan, yaitu factor ekonomi, sosial dan budaya yang selaras dengan sistem hukum yang dijelaskan dalam teori friedman yang membentuk kerangka hukum yang terdiri dari hukum sebagai substansi, struktur dan budaya.

\section{SARAN}

Berdasarkan hal - hal yang telah diuraikan diatas maka penulis dapat memberikan saran-saran yaitu

1. Perlu dilakukan sosialisasi kepada masyarakat perihal Garis Sempadan Jalan yang secara khusus untuk Kabupaten Kuningan diatur dalam Peraturan Daerah Kabupaten Kuningan Nomor 8 Tahun 2013 mengenai Garis Sempadan Jalan.

2. Peningkatan kualitas public service khususnya dalam proses permohonan Izin Mendirikan Bangunan (IMB) agar lebih mendetail sehingga fungsi lahan dapat tepat guna.

\section{DAFTAR PUSTAKA}

Amidjojo, Bintoro Cokro. 1990. Pengantar Administrasi Pembangunan. Jakarta : LP3ES.

Budiman, Haris. Pelanggaran Hak Asasi Manusia Dalam Kebijakan Daerah Di Bidang Tata Ruang Di Kabupaten Kuningan, Jurnal Unifikasi, ISSN 
UNIFIKASI : Jurnal IImu Hukum, Volume 05 Nomor 01, Januari 2018

2354-5976 Vol. 04 Nomor 01 Januari 2017, hlm. 25-34. https://doi.org/10.25134/unifikasi.v4 i1.475.

C.S.T., Kansil. 2005. Sistem Pemerintahan Indonesia, Jakarta : PT. Bumi Aksara.

Direktorat Pekerjaan Umum. 2012. Keselamatan Jalan. Jakarta : Penerbit Departemen Pekerjaan Umum.

Hardiyatmo, Hary Christady. 2015, Pemeliharaan Jalan Raya, Yogyakarta : Gadjah Mada University Press.

Isworo, Ety. Tinjauan Yuridis Pelaksanaan Penertiban Hunian Liar Di Kota Solo, Jurisprudence, VOL . 1, NO . 1. Juli 2012 : 89 -102. Surakarta : Universitas Muhamadiyah Surakarta.

MaCandrews, Colin dan Ichlasul Amal. 1993. Hubungan Pusat Daerah dalam pembangunan. Jakarta : PT Raja grafindo Persada.

Maryono, Agus. 2013. Pengelolaan Kawasan Sempadan Sungai. Yogyakarta : Gadjah Mada University Press.

Nurcholis, Hanif. 2005. Teori dan Praktik Pemerintahan dan Otonomi Derah. Jakarta: Gramedia Widiasarana Indonesia.

Redaksi, 2011, Peraturan Pemerintah RI : Bangunan Gedung dan Izin mendirikan Bangunan , Jakarta: Fokus Media.

Soekamto, Soerjono. tanpa tahun, Metodologi Penelitian dan Penulisan Hukum, Jakarta : Raja grafindo.

Santos, Eko Budi. Navitas, Prananda. 2016, Perspektif Pengembangan Wilayah \& Kota, Jakarta: Teknosain.

Soekamto, Soerjono. tanpa tahun, Metodologi Penelitian dan Penulisan Hukum, Jakarta : Raja grafindo.

Subekti, R. Beberapa Pemikiran Mengenai Sistem Hukum Nasional yang akan
p-ISSN 2354-5976, e-ISSN 2580-7382

https://journal.uniku.ac.id/index.php/unifikasi

Datang, Kertas kerja pada Seminar Hukum Nasional IV, Jakarta 1979.

Sutendi, Adrian. 2011. Hukum Perizinan Dalam Sektor Pelayanan Publik. Jakarta : Sinar Grafika.

Trubus Wahyudi, Artikel lepas dengan judul Urgensi Sistem Hukum di Indonesia dalam Perspektif Pembentukan Hukum Nasional yang Berfalsafah Pancasila.

Undang-Undang Pokok Agraria Nomor 5 Tahun 1960

Undang -Undang Nomor 28 Tahun 2002 Tentang Bangunan Gedung

Undang-Undang Nomor 38 Tahun 2004 Tentang Jalan.

Undang-Undang Nomor 26 Tahun 2007 tentang Penataan Ruang

Undang-Undang Nomor 23 Tahun 2014 tentang Pemerintah Daerah

Peraturan Daerah ProvinsiJawa Barat Nomor 3 Tahun 2009 Tentang Garis Sempadan Jalan.

Peraturan Daerah Kabupaten Kuningan Nomor 8 tahun 2013 Tentang Garis Sempadan Jalan. 